Check for updates

Cite this: RSC Adv., 2019, 9, 35165

\title{
Stabilization of two conformers via intra- or inter- molecular hydrogen bonds in a dinuclear vanadium(v) complex with a pendant Schiff base: theoretical insight $\uparrow$
}

\author{
Snehasish Thakur, ${ }^{a}$ Michael G. B. Drew, ${ }^{\text {b }}$ Antonio Franconetti, (D) ${ }^{c}$ \\ Antonio Frontera (D) and Shouvik Chattopadhyay (D) *a
}

\begin{abstract}
A dinuclear vanadium(v) complex, $(\mu-\mathrm{O})_{2}[\mathrm{~V}(\mathrm{O})(\mathrm{L})]_{2}$, [where $\mathrm{HL}=2$-methoxy-6-((2-(2-hydroxyethylamino) ethylimino)methyl)phenol] has been synthesized and characterized by spectral and elemental analysis. A single crystal X-ray diffraction study confirms it structure. Two different conformations, stabilized via either intra- or inter-dinuclear hydrogen bonding interactions, co-exist in the solid-state structure. The energies of these intra- or inter-dinuclear hydrogen bonding interactions have been estimated by Density functional theory (DFT) calculations. A 'Non-covalent interaction' (NCl) plot has also been used

to characterize these interactions.
\end{abstract}

Received 2nd September 2019

Accepted 17th September 2019

DOI: $10.1039 / \mathrm{c} 9 \mathrm{ra} 07006 \mathrm{k}$

rsc.li/rsc-advances

\section{Introduction}

The ability of vanadium complexes to catalyze oxidations and oxo transfer reactions has provoked the interest of synthetic inorganic chemists for the preparation of various vanadium complexes. ${ }^{1}$ Many of these complexes have different nuclearity and coordination environments. ${ }^{2}$ Steric bulk of the substituent on the benzene ring of a ligand may prevent dimerization of the complex and may therefore be used to manipulate the coordination geometry and/or number of vanadium atoms in the final structure by preventing dimerization. ${ }^{3}$ Usually, final structures of metal complexes have been argued to be dependent on many factors e.g. metal-ligand ratio, solvent used, reaction temperature, and last but not the least, weak forces, such as hydrogen bonding and $\pi \cdots \pi$ stacking interactions. ${ }^{4}$ These non-covalent interactions are responsible for determining the threedimensional structures of chemical and biological systems as a consequence of their specificity and directionality. ${ }^{5}$ While covalent bonds, once formed, are stable under usual conditions and can only be broken by providing sufficient energy, hydrogen bonds are formed reversibly and their strength depends on the

${ }^{a}$ Department of Chemistry, Inorganic Section, Jadavpur University, Kolkata 700032 , India. E-mail: shouvik.chem@gmail.com

${ }^{b}$ School of Chemistry, The University of Reading, P.O. Box 224, Whiteknights, Reading RG6 6AD, UK

${ }^{c}$ Departament de Quimica, Universitat de les Illes Balears, Crta. De Valldemossa km 7.5, 07122 Palma, Baleares, Spain

$\dagger$ Electronic supplementary information (ESI) available. CCDC 1879621 and 1956388 contain the supplementary crystallographic data for the two complexes. For ESI and crystallographic data in CIF or other electronic format see DOI: $10.1039 / \mathrm{c} 9 \mathrm{ra} 07006 \mathrm{k}$ chemical environment, such as the solvent or temperature. ${ }^{6}$ Hydrogen bonding is indeed the most significant directional inter-molecular interaction which has successfully aroused the interest of solid state chemists for years. ${ }^{7-14}$ Both intra- and inter-molecular hydrogen bonding interactions can be responsible for the generation of different conformations of a single substance. For example, two different secondary structures $(\alpha-$ helices and $\beta$-sheets) of biological macromolecules (e.g. proteins) may result from the competition between these two types of interactions. When short-range $\mathrm{N}-\mathrm{H} \cdots \mathrm{O}=\mathrm{C}$ intermolecular hydrogen bonds are favored (energetically) over long-range $\mathrm{N}-\mathrm{H} \cdots \mathrm{O}=\mathrm{C}$ intra-molecular hydrogen bonds, dimer ( $\beta$-sheet) formation is preferred over self-assembled amino acid monomers $\left(\alpha\right.$-helix). ${ }^{8}$ Numerous hydrogen bonded architectures of different coordination complexes also exist in literature. ${ }^{9-15}$ Rochon et al. synthesized a coordination complex of manganese, where coexisting intra- and inter-molecular hydrogen bonds result in infinite triple chains and in two equivalent interpenetrating infinite $2 \mathrm{D}$ sheets, respectively. ${ }^{9}$ Hydrogen bonding interaction involving pendant side arms in the complex moiety is also a matter of interest for coordination chemists. ${ }^{10-15}$ Usually pendant arms are bonded directly to the donor atoms so that they can affect the nature of its metal ion coordination. ${ }^{10}$ But interesting structural motifs arise when they are uncoordinated to the metal centre and remain as dangling groups. They may consist of flexible components i.e. alkyl chain containing functional groups like amines, alcohols, amides and carboxyl or aromatic groups with other potential donors. ${ }^{11}$ There are quite a few instances involving macrocyclic ligands bearing first row transition metal complexes where the unbound side arms play a pivotal role in establishing intra- and 
inter-molecular hydrogen bonding interactions. ${ }^{12,13}$ Aneetha et al. discussed the hydrogen bonding interaction in a copper(II) complex of a macrocyclic tetraaza ligand, where protons of pendant $-\mathrm{CH}_{2}-\mathrm{CH}_{2}-\mathrm{OH}$ side arm establish hydrogen bonds with non coordinated perchlorate anions in the moiety, ${ }^{12}$ whereas Nagata et al. described intra-molecular hydrogen bonding interaction of a pendant $-\mathrm{CH}_{2}-\mathrm{CO}-\mathrm{NH}_{2}$ group within the molecule. ${ }^{13}$ Literature shows numerous $3 \mathrm{~d}$ series transition metal coordination complexes,${ }^{14}$ including vanadium,${ }^{15}$ having uncoordinated hydroxyethyl $\left(-\mathrm{CH}_{2}-\mathrm{CH}_{2}-\mathrm{OH}\right)$ moiety involved in intra- or inter-molecular hydrogen bonding interactions. However, computational techniques have scarcely been implemented to identify the energy involved in those kind of hydrogen bonding interactions. Construction of two different hydrogen bonded frameworks exploiting the pendant side arm of the ligand moiety in any vanadium complex has also not been reported prior to the present work. In contrast, the recent vanadium(v) investigations reported in the literature are focused on elucidating the behavior of hydrophobic complexes in terms of their interaction with erythrocytes, ${ }^{16}$ interface model systems, their impact in anti-cancer activities ${ }^{\mathbf{1 7}}$ and enzyme inhibitors. ${ }^{18}$ Moreover, vanadium(v) complexes derived from hydrazone compounds have been used as antimicrobial complexes $^{19}$ and also as catalysts for the oxidation of cyclohexane $^{20}$ and the oxidative bromination of salicylaldehyde, ${ }^{21}$ which were rationalized using DFT and TDDFT calculations.

In this work, a potentially pentadentate Schiff base ligand is used to form a dinuclear vanadium(v) complex, in which the Schiff base behaves as a tridentate ligand keeping its remaining binding sites pendant. Two different conformers of the complex have been stabilized by intra- or inter-molecular hydrogen bonds in its solid state structure. In one conformer, the vanadyl oxygen atoms are involved in intra-dinuclear hydrogen bonding with the pendant hydroxyl group of the Schiff base. The other conformer forms 1D chain via inter-dinuclear hydrogen bonding interactions among vanadyl oxygen atoms and the pendant hydroxyl group of the Schiff base. DFT calculations have been utilized to estimate the energies involved in these interactions. NCI plot index computational tool further assists relevant theoretical findings.

\section{Experimental section}

VOSO $_{4} \cdot 5 \mathrm{H}_{2} \mathrm{O}$ was purchased from Loba Chemie Pvt. Ltd. and was of reagent grade. All other starting materials were commercially available, reagent grade, and used as purchased from Sigma-Aldrich without further purification.

\subsection{Preparation of $(\mu-O))_{2}[\mathrm{~V}(\mathrm{O})(\mathrm{L})]_{2}$}

The potentially pentadentate ligand, HL, has been prepared by refluxing 3-methoxysalicylaldehyde (152 $\mathrm{mg}, 1 \mathrm{mmol})$ with $\mathrm{N}$-(2hydroxyethyl)ethylenediamine $(0.10 \mathrm{~mL}, 1 \mathrm{mmol})$ in $\mathrm{CH}_{3} \mathrm{CN}(10$ $\mathrm{mL}$ ) for $c a .1 \mathrm{~h}$. The ligand has not been separated from the reaction mixture and has directly been used for the preparation of the complex. A $20 \mathrm{~mL} \mathrm{CH} \mathrm{CH}_{3} \mathrm{CN}$ solution of $\mathrm{VOSO}_{4} \cdot 5 \mathrm{H}_{2} \mathrm{O}$ (253 $\mathrm{mg}, 1 \mathrm{mmol}$ ) has been added thereafter to the $15 \mathrm{~mL}$
$\mathrm{CH}_{3} \mathrm{CN}$ solution of the ligand and the resulting solution has then been refluxed for $c a .3 \mathrm{~h}$. It was cooled to room temperature, subsequently filtered and kept for crystallization. Single crystals, appropriate for X-ray diffraction, were obtained after a week on slow evaporation of the filtrate $\left(\mathrm{CH}_{3} \mathrm{CN}\right.$ solution) in open atmosphere.

Yield: $227 \mathrm{mg}$ (71\%), based on vanadium; anal. calc. for $\mathrm{C}_{24} \mathrm{H}_{34} \mathrm{~N}_{4} \mathrm{O}_{10} \mathrm{~V}_{2}(\mathrm{FW}=640.43): \mathrm{C}, 45.01 ; \mathrm{H}, 5.35 ; \mathrm{N}, 8.75 \%$; found: C, 44.9; H, 5.1; N, 8.9\%; FT-IR $\left(\mathrm{KBr}, \mathrm{cm}^{-1}\right): 3393\left(\tilde{v}_{\mathrm{O}-\mathrm{H}}\right)$, $3148\left(\tilde{v}_{\mathrm{N}-\mathrm{H}}\right), 1634\left(\tilde{v}_{\mathrm{C}=\mathrm{N}}\right), 934\left(\tilde{v}_{\mathrm{V}=\mathrm{O}}\right)$. UV-vis, $\lambda_{\max }(\mathrm{nm}),\left[\varepsilon_{\max }(\mathrm{L}\right.$ $\left.\left.\mathrm{mol}^{-1} \mathrm{~cm}^{-1}\right)\right]\left(\mathrm{CH}_{3} \mathrm{CN}\right): 388\left(4.7 \times 10^{3}\right)$.

${ }^{1} \mathrm{H}$ NMR (DMSO-d ${ }_{6}, 400 \mathrm{MHz}$ ) (ppm) $\delta: 8.89$ (singlet, $2 \mathrm{H}$, imine $\mathrm{H},-\mathrm{CH}=\mathrm{N}$ ), 6.72-7.14 (multiplet, $6 \mathrm{H}$, aromatic $\mathrm{C}-\mathrm{H}$ ), 5.55 (broad singlet, 2H, hydroxyl $-\mathrm{OH}$ ), 4.87 (multiplet, $2 \mathrm{H}$, $-\mathrm{NH}$ ), 3.13-4.03 (multiplet, $14 \mathrm{H}$, methylene $\mathrm{CH}_{2}$ ).

${ }^{13} \mathrm{C}$ NMR (DMSO-d 6 , $300 \mathrm{MHz}$ (ppm) $\delta: 48.619$ [-C(43)], $55.968 \quad[-\mathrm{C}(41)], \quad 57.952-58.820 \quad[-\mathrm{C}(40), \quad-\mathrm{C}(44), \quad-\mathrm{C}(341)]$, $116.794,116.948[-\mathrm{C}(35),-\mathrm{C}(36)], 120.828$ [-C(34)], 125.542 [-C(37)], 150.209 [-C(32)], 155.999 [-C(33)], 168.772 [-C(38)].

Crystal data: formula $=\mathrm{C}_{24} \mathrm{H}_{34} \mathrm{~N}_{4} \mathrm{O}_{10} \mathrm{~V}_{2}$, formula weight $=$ 640.43 , temperature $(\mathrm{K})=150$, crystal system $=$ triclinic, space group $=P \overline{1}, a=6.8424(6) \AA, b=9.4438(8) \AA, c=21.2231(3) \AA$, $\alpha=102.009(7)^{\circ}, \beta=98.937(7)^{\circ}, \gamma=90.685(7)^{\circ}, Z=2, d_{\text {calc }}(\mathrm{g}$ $\left.\mathrm{cm}^{-3}\right)=1.607, \mu\left(\mathrm{mm}^{-1}\right)=0.771, F(000)=664$, total reflections $=9447$, unique reflections $=7403$, observed data $[I>2 \sigma(I)]=$ 5321 , no. of parameters $=365, R($ int $)=0.035, R_{1}, \mathrm{w} R_{2}$ (all data) $=0.1002,0.1432, R_{1}, \mathrm{w} R_{2}[I>2 \sigma(I)]=0.0638,0.1281$.

\subsection{Physical measurements}

Elemental analyses (carbon, hydrogen and nitrogen) were performed using a PerkinElmer 240C elemental analyzer. IR spectrum in $\mathrm{KBr}\left(4500-500 \mathrm{~cm}^{-1}\right)$ was recorded with a PerkinElmer Spectrum Two spectrophotometer. Electronic spectrum in $\mathrm{CH}_{3} \mathrm{CN}$ was recorded on a Shimadzu UV-1700 UV-vis spectrophotometer. The magnetic susceptibility measurement was performed with an EG and PAR vibrating sample magnetometer, model 155 at room temperature $(300 \mathrm{~K})$ in a $5000 \mathrm{G}$ magnetic field, and diamagnetic corrections were performed using Pascal's constants. ${ }^{1} \mathrm{H}$ NMR spectrum in DMSO- $\mathrm{d}_{6}$ solvent was recorded in a JEOL $400 \mathrm{MHz}$ NMR instrument (Fig. S4, $\mathrm{ESI} \dagger) .{ }^{13} \mathrm{C}$ NMR spectrum of the complex in DMSO-d $\mathrm{d}_{6}$ solvent was recorded in a BRUKER $300 \mathrm{MHz}$ NMR Spectrometer (Fig. S5, ESI $\dagger$ ).

\subsection{X-ray crystallography}

A suitable single crystal of the complex was picked and mounted on a glass fiber, and diffraction intensities were measured with an Oxford Diffraction X-Calibur diffractometer, equipped with Mo $\mathrm{K}_{\alpha}$ radiation $(\lambda=0.71073 \AA, 50 \mathrm{kV}, 40 \mathrm{~mA})$ at temperature $150 \mathrm{~K}$. Data collection and reduction were performed with the Oxford Diffraction CrysAlis system. Structure of the complex was solved by direct method and refined by full-matrix least squares on $F^{2}$, using the SHELX-2016/6 package. ${ }^{22}$ Absorption correction type is empirical with ABSPACK program of Oxford Diffraction Ltd. Non-hydrogen atoms were refined anisotropically. Hydrogen atoms attached to nitrogen and oxygen atoms 
were located by difference Fourier maps. All other hydrogen atoms were placed in their geometrically idealized positions and constrained to ride on their parent atoms. Programs used: SHELX-2016/6,,$^{22}$ PLATON, ${ }^{23} \quad$ WINGX $^{24}$ ORTEP, ${ }^{25}$ and MERCURY. ${ }^{26}$

\subsection{Theoretical methods}

The energy of the complex included in this study was calculated at the M06-2X/def2-TZVP level of theory using the crystallographic coordinates. For calculation, the GAUSSIAN-09 program has been used..$^{27}$ This level of theory and methodology has been successfully used by us to study similar interactions. ${ }^{28}$ The basis set superposition error for the calculation of interaction energies has been corrected using the counterpoise method. ${ }^{29}$ The NCI plot $^{30}$ isosurfaces have been used to characterize noncovalent interactions. They correspond to both favorable and unfavorable interactions, as differentiated by the sign of the second density Hessian eigenvalue and defined by the isosurface color. The color scheme is a red-yellow-green-blue scale with red for $\rho_{\text {cut }}{ }^{+}$(repulsive) and blue for $\rho_{\text {cut }}{ }^{-}$(attractive).

\subsection{Hirshfeld surface analysis}

Hirshfeld surfaces, ${ }^{31}$ mapped with $d_{\text {norm }}$, shape index and curvedness along with $2 \mathrm{D}$ fingerprint ${ }^{32}$ plots were calculated with the help of Crystal Explorer ${ }^{33}$ software using CIF of the complex. Bond lengths to hydrogen atoms were set to standard values. A typical Hirshfeld surface is represented customarily by a set of surface points. Two parameters are essential to provide information about relevant contact distances from each point; $d_{\mathrm{i}}$ represents the distance from the surface to the nearest atom interior to the surface, while $d_{\mathrm{e}}$ represents the distance from the surface to the nearest atom exterior to the surface. The normalized contact distance $\left(d_{\text {norm }}\right)$ based on $d_{\mathrm{e}}$ and $d_{\mathrm{i}}$ is given by

$$
d_{\text {norm }}=\frac{\left(d_{\mathrm{i}}-r_{\mathrm{i}}^{\mathrm{vdw}}\right)}{r_{\mathrm{i}}^{\mathrm{vdw}}}+\frac{\left(d_{\mathrm{e}}-r_{\mathrm{e}}^{\mathrm{vdw}}\right)}{r_{\mathrm{e}}^{\mathrm{vdw}}}
$$

where $r_{\mathrm{i}}^{\mathrm{vdw}}$ and $r_{\mathrm{e}}^{\mathrm{vdw}}$ are the van der Waals radii of the atoms. $d_{\text {norm }}$ was negative or positive depending on inter-molecular contacts which were shorter or longer than the van der Waals separations. It also demonstrated a surface with a red-whiteblue color scheme, where bright red spots highlighted shorter contacts, white areas represented contacts around the van der
Waals separation, and blue regions were the areas where close contacts were missing. Hirshfeld surface is characteristic for a given crystal structure and set of spherical atomic electron densities, ${ }^{34}$ and it was this property which indicated the probability of achieving additional insight into the inter-molecular interaction of molecular crystals.

\section{Results and discussions}

\subsection{Synthesis}

3-methoxysalicylaldehyde and $N$-(2-hydroxyethyl)ethylenediamine have been refluxed in $\mathrm{CH}_{3} \mathrm{CN}$ medium to synthesize a potentially pentadentate Schiff base ligand, $\mathbf{H L}$, following a standard literature procedure. ${ }^{35}$ A solution of $\operatorname{VOSO}_{4} \cdot 5 \mathrm{H}_{2} \mathrm{O}$ in $\mathrm{CH}_{3} \mathrm{CN}$ has then been added to the synthesized ligand solution to prepare a dinuclear vanadium(v) complex, $(\boldsymbol{\mu}-\mathbf{O})_{2}[\mathbf{V}(\mathbf{O})(\mathbf{L})]_{2}$. HL has been found to coordinate vanadium(v) in a tridentate fashion in the complex. Vanadium(Iv) in the precursor salt is oxidized to vanadium(v) through oxidation by atmospheric air with associated reduction of atmospheric oxygen to water. The effort to synthesize the complex in inert atmosphere $\left(\mathrm{N}_{2}\right.$ environment) did not succeed. This supported the involvement of molecular oxygen in the oxidation of vanadium(Iv). Formation of the complex has been shown in Scheme 1.

\subsection{Description of structure of $(\mu-O)_{2}[\mathrm{~V}(\mathrm{O})(\mathrm{L})]_{2}$}

The complex crystallizes in triclinic space group $P \overline{1}$. The asymmetric unit of the complex contains two independent subunits, named 'A' and 'B'. An outlook of the complex consisting of both subunits with selective atom numbering scheme is demonstrated in Fig. 1. In each subunit, one half of the molecule, constituting the asymmetric part of the structure, is related to the other half by the center of symmetry. Vanadium(v) centers are hexa-coordinated in both subunits. In the $\mathrm{V}_{2} \mathrm{O}_{2}$ core of each subunit, one vanadium(v)-oxygen distance is shorter $[\mathrm{V}(1)-\mathrm{O}(1)$ $=1.675(2) \AA ̊$ in subunit 'A'; $\mathrm{V}(2)-\mathrm{O}(3)=1.691(2) \AA$ in subunit 'B'] compared to the other vanadium(v)-oxygen distance $\left[\mathrm{V}(1)-\mathrm{O}\left(1^{a}\right)\right.$ $=2.272(2) \AA(a=1-x, 2-y, 1-z)$ in subunit ' $A$ '; $\mathrm{V}(2)-\mathrm{O}\left(3^{b}\right)=$ $2.337(2) \AA(b=-x, 1-y,-z)$ in subunit 'B']. The short vanadium-oxygen distances correspond to a $\mathrm{V}=\mathrm{O}$ double bond. The vanadium(v) centers, $\mathrm{V}(1)$ and $\mathrm{V}\left(1^{a}\right)$ in subunit ' $\mathbf{A}$ ' are separated by a distance of 3.0663(7) $\AA$, whereas $\mathrm{V}(2)$ and $\mathrm{V}\left(2^{b}\right)$ in subunit 'B' are $3.1437(7) \AA$ apart from each other. These values

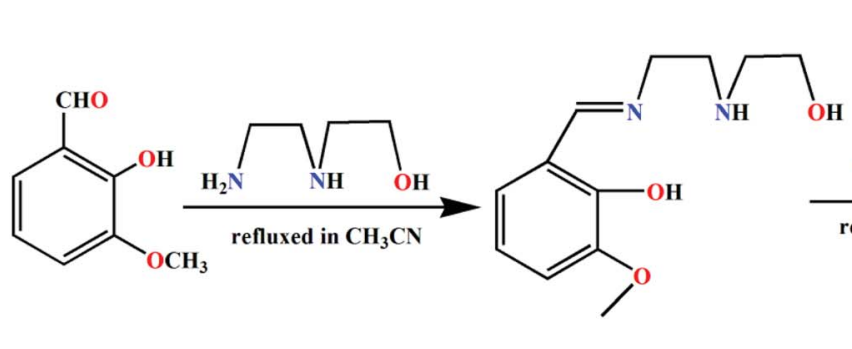

HL

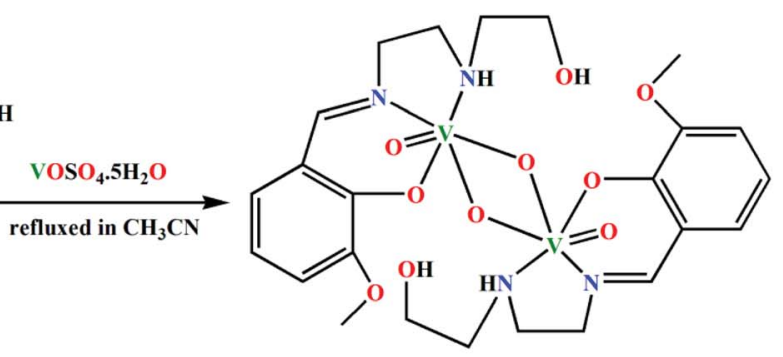

$(\mu-\mathbf{O})_{2}[\mathrm{~V}(\mathrm{O})(\mathbf{L})]_{2}$

Scheme 1 Synthesis of the ligand $\mathrm{HL}$ and the complex $(\mu-\mathrm{O})_{2}[\mathrm{~V}(\mathrm{O})(\mathrm{L})]_{2}$. 


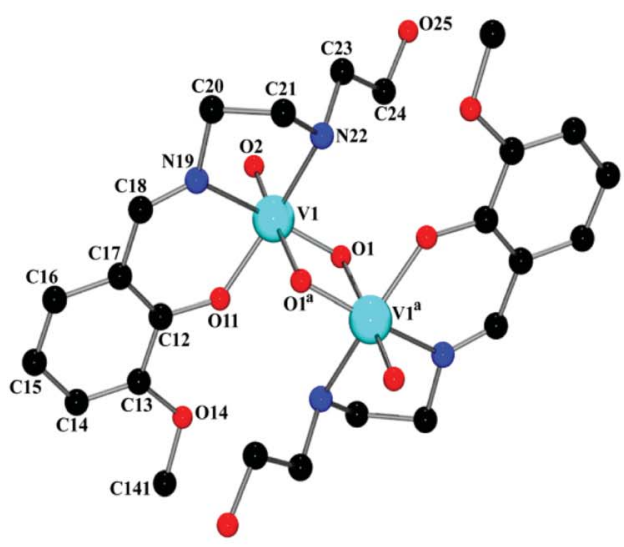

Subunit 'A'

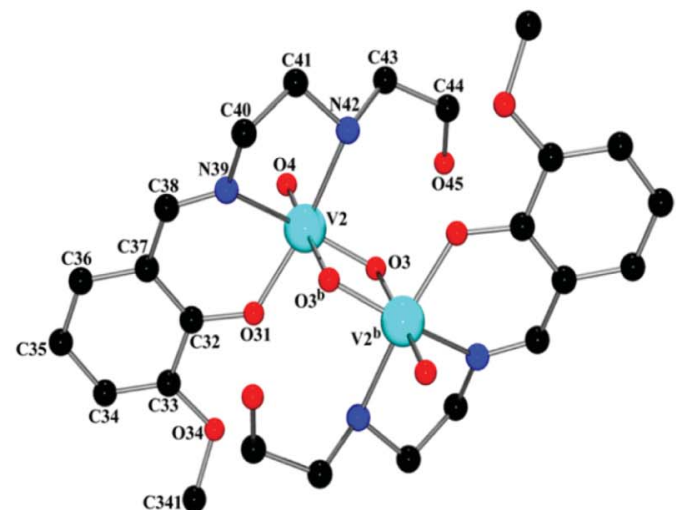

Subunit 'B'

Fig. 1 Perspective view of the subunits ' $A$ ' and 'B' of the complex with selective atom numbering scheme. Hydrogen atoms have not been shown. All the symmetry related atoms have not been labeled for clarity. Symmetry transformation: ${ }^{a}=1-x, 2-y, 1-z ;{ }^{b}=-x, 1-y,-z$. Selected bond lengths $(\AA): V(1)-O(1)=1.675(2) ; V(1)-O(2)=1.626(2) ; V(1)-O(11)=1.912(2) ; V(1)-N(19)=2.162(3) ; V(1)-N(22)=2.158(3) ; V(1)-$ $\mathrm{O}\left(1^{a}\right)=2.272(2)$ [for subunit ' $\left.\mathrm{A}^{\prime}\right]$. $\mathrm{V}(2)-\mathrm{N}(42)=2.182(3) ; \mathrm{V}(2)-\mathrm{O}\left(3^{b}\right)=2.337(2) ; \mathrm{V}(2)-\mathrm{O}(31)=1.898(2) ; \mathrm{V}(2)-\mathrm{O}(3)=1.691(2) ; \mathrm{V}(2)-\mathrm{O}(4)=1.610(2)$; $\mathrm{V}(2)-\mathrm{N}(39)=2.133(3)$ [for subunit 'B'].

correspond to the values found in analogous dinuclear vana$\operatorname{dium}(\mathrm{v})$ complexes. ${ }^{36}$ In both subunits, vanadium(v) centers show a distorted octahedral geometry. The slightly distorted octahedra about vanadium(v) centers are constituted by iminic nitrogen atoms, amine nitrogen atoms, phenoxy oxygen atoms, terminal oxo groups [N(19), $\mathrm{N}(22), \mathrm{O}(11)$, and $\mathrm{O}(2)$ for subunit 'A'; N(39), N(42), O(31) and O(4) for subunit 'B'] and remaining two bridging oxygen atoms in each subunit $\left[\mathrm{O}(1)\right.$ and $\mathrm{O}\left(1^{a}\right)$ in subunit ' $\mathbf{A}$ ', $\mathrm{O}(3)$ and $\mathrm{O}\left(3^{b}\right)$ in subunit ' $\mathbf{B}$ '], related by their respective center of symmetries. Thus, the coordination sphere of the vanadium(v) centers in each subunit is comprised of six unique heteroatom types: vanadyl oxo atoms, two bridging oxo atoms at short and long distances, a phenoxy oxygen atom and imine and amine nitrogen atoms. The $\mathrm{O}(2)-\mathrm{V}(1)-\mathrm{O}(1)$ angle of $106.41(1)^{\circ}$ in subunit ' $A$ ' and the analogous $\mathrm{O}(3)-\mathrm{V}(2)-\mathrm{O}(4)$ angle of $107.51(1)^{\circ}$ in subunit 'B' (Table S1, ESI $\dagger$ ) indicate significant double bond characters of the bonds $\mathrm{V}(1)-\mathrm{O}(1)$ and $\mathrm{V}(1)-\mathrm{O}(2)$ in subunit ' $\mathrm{A}$ ' and $\mathrm{V}(2)-\mathrm{O}(3)$ and $\mathrm{V}(2)-\mathrm{O}(4)$ in subunit 'B', respectively. ${ }^{37}$ The chelating angles, $\mathrm{N}(19)-\mathrm{V}(1)-\mathrm{N}(22)$ and $\mathrm{N}(19)-\mathrm{V}(1)-\mathrm{O}(11)$ of $77.84(10)^{\circ}$ and $84.66(10)^{\circ}$, respectively in subunit 'A' and $\mathrm{N}(39)-\mathrm{V}(2)-\mathrm{N}(42)$ and $\mathrm{N}(39)-\mathrm{V}(2)-\mathrm{O}(31)$ of $78.27(10)^{\circ}$ and $83.29(10)^{\circ}$, respectively in subunit ' $\mathbf{B}$ ', indicate the distortion of the octahedral geometry around the vanadium(v) centers. ${ }^{38}$ The dimerization of the monomeric $\mathrm{VO}_{2} \mathrm{~L}$ units in both subunits is motivated by the electron deficiency and oxophilicity of vanadium(v) centers. ${ }^{39}$

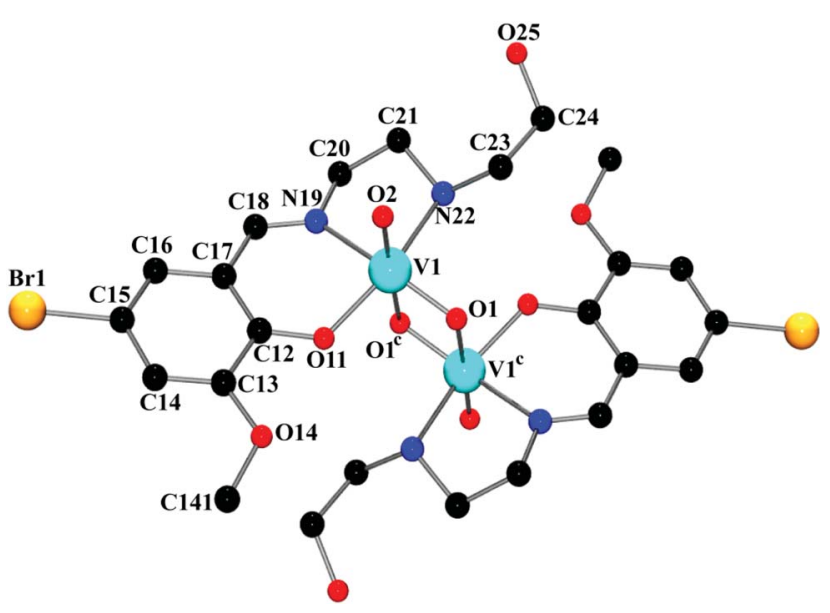

Fig. 2 Perspective view of $(\mu-\mathrm{O})_{2}\left[\mathrm{~V}(\mathrm{O})\left(\mathrm{L}^{1}\right)\right]_{2}$ with selective atom numbering scheme. Hydrogen atoms have not been shown. All the symmetry related atoms have not been labeled for clarity. Symmetry transformation: ${ }^{c}=1-x, 1-y, 1-z$.

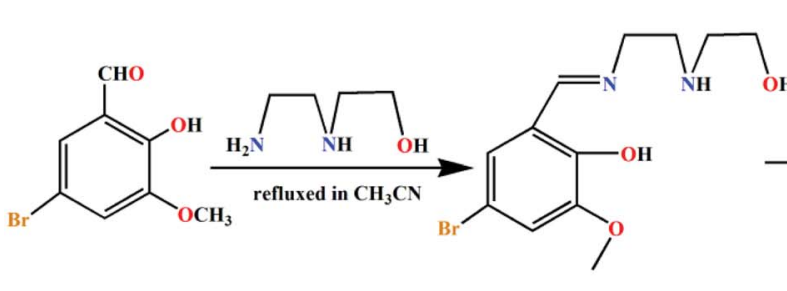

HL $^{1}$

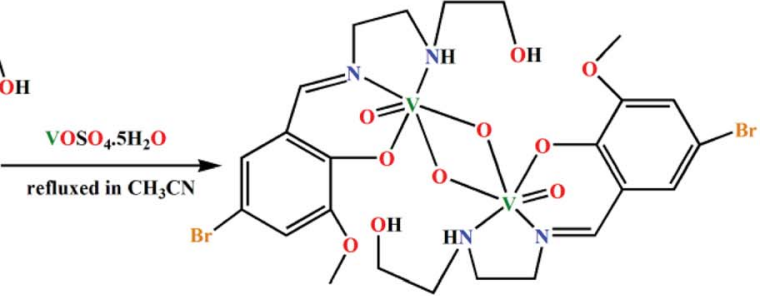

$(\mu-\mathbf{O})_{2}\left[\mathbf{V}(\mathbf{O})\left(\mathbf{L}^{1}\right)\right]_{2}$

Scheme 2 Synthetic route to the ligand $\mathrm{HL}^{1}$ and the complex $(\mu-\mathrm{O})_{2}\left[\mathrm{~V}(\mathrm{O})\left(\mathrm{L}^{1}\right)\right]_{2}$. 
Table 1 Examples of reported $\mu_{2}$-oxo bridged dinuclear vanadium complexes having different substituents at different positions in the benzene ring of the ligand moiety ${ }^{a}$

\begin{tabular}{llll}
\hline Complexes & Crystal system & Space group & Structure
\end{tabular}

\begin{tabular}{|c|c|c|c|}
\hline$(\mu-O)_{2}\left[V(O)\left(L^{2}\right)\right]_{2}$ & Monoclinic & $P 2_{1} / c$ & $42 a$ \\
\hline$(\boldsymbol{\mu}-\mathbf{O})_{2}\left[\mathbf{V}(\mathbf{O})\left(\mathbf{L}^{3}\right)\right]_{2}$ & Monoclinic & $P 2_{1} / n$ & $42 b$ \\
\hline$(\mu-\mathbf{O})_{2}\left[\mathbf{V}(\mathbf{O})\left(\mathbf{L}^{\mathbf{4}}\right)\right]_{2}$ & Monoclinic & $P 2_{1} / c$ & $42 b$ \\
\hline$(\boldsymbol{\mu}-\mathbf{O})_{2}\left[\mathbf{V}(\mathbf{O})\left(\mathbf{L}^{5}\right)\right]_{2}$ & Monoclinic & $P 2_{1} / c$ & $42 c$ \\
\hline$(\mu-\mathbf{O})_{2}\left[\mathbf{V}(\mathbf{O})\left(\mathbf{L}^{6}\right)\right]_{2}$ & Monoclinic & $P 2_{1} / n$ & $42 d$ \\
\hline$(\boldsymbol{\mu}-\mathbf{O})_{2}\left[\mathbf{V}(\mathbf{O})\left(\mathbf{L}^{7}\right)\right]_{2} \cdot \mathbf{b p y}$ & Triclinic & $P \overline{1}$ & $42 e$ \\
\hline$(\mu-\mathbf{O})_{2}\left[\mathbf{V}(\mathbf{O})\left(\mathbf{L}^{8}\right)\right]_{2}$ & Triclinic & $P \overline{1}$ & $42 f$ \\
\hline
\end{tabular}

${ }^{a} \mathbf{H L}^{2}=$ 2-((2-(2-hydroxyethylamino)ethylimino)methyl)phenol. $\mathbf{H L}^{3}=$ 2-ethoxy-6-((2-(2-hydroxyethylamino)ethylimino)methyl)phenol. $\mathbf{H L}^{\mathbf{4}}=4$ chloro-2-((2-(2-hydroxyethylamino)ethylimino)methyl)phenol. $\mathbf{H L}^{\mathbf{5}}=4$-fluoro-2-((2-(2-hydroxyethylamino)ethylimino)methyl)phenol. HL $^{6}=2$ bromo-4-chloro-6-((2-(2-hydroxyethylamino)ethylimino)methyl)phenol. $\mathbf{H L}^{\mathbf{7}}=2$-((2-(2-hydroxyethylamino)ethylimino)methyl)-6-methylphenol. $\mathbf{H L}^{7}=2-((2-(2$-hydroxyethylamino $)$ ethylimino)phenylmethyl)-5-methoxyphenol.

This complex has a five membered puckered chelate ring in each subunit of ' $\mathbf{A}$ ' and ' $\mathbf{B}$ '. The ring shape is usually assigned explicitly by the Cremer-Pople puckering parameters. ${ }^{40}$
Puckering parameters are defined by the actual variations in ring shape, which are variations in the distances of the atom from a mean plane, and that the bond lengths and covalent 
bond angles vary to a more limited extent with less effect on the overall shape. The deviation $(q)$ is customarily expressed in angstrom units. For six-membered rings, there are two additional parameters, $\theta$ and $\varphi$. The $\theta$ parameter suggests the type of shape, such as chair, half chair, boat, or skew, and the $\varphi$ parameter denotes where the deviations from the mean plane are greatest. ${ }^{\mathbf{4 1}}$

The saturated five membered chelate rings, $\mathrm{V}(1)-\mathrm{N}(19)-$ $\mathrm{C}(20)-\mathrm{C}(21)-\mathrm{N}(22)$ in subunit 'A' and $\mathrm{V}(2)-\mathrm{N}(39)-\mathrm{C}(40)-\mathrm{C}(41)-$ $\mathrm{N}(42)$ in subunit ' $\mathbf{B}$ ' assume a half chair and an envelope conformation respectively, having the puckering parameters $q$ $=0.443(4) \AA \circ ; \varphi=271.3(3)^{\circ}$ for subunit 'A' and $q=0.409(4) \AA ;$ $=90.1(4)^{\circ}$ for subunit ' $\mathbf{B}$ '. It is noteworthy that the hydroxyl group of the pendant hydroxyethyl $\left(-\mathrm{CH}_{2}-\mathrm{CH}_{2}-\mathrm{OH}\right)$ side arm of the ligand remains uncoordinated. It makes the ligand a tridentate donor for this complex (the ligand is actually a potentially pentadentate one). Moreover, from the structural point of view, it is evident that in subunit ' $\mathbf{A}$ ', the unbound hydroxyl groups are extended away from the vanadium(v) centers, while in subunit 'B', they are pointed inwards the metal centers. This differential orientation of the uncoordinated hydroxyl groups of the pendant $-\mathrm{CH}_{2}-\mathrm{CH}_{2}-\mathrm{OH}$ arms may be the reason of their involvement in inter- and intra-molecular hydrogen bonding interactions in subunit ' $\mathbf{A}$ ' and subunit 'B', respectively.

In order to check the substituent effect of ligand on the final structure of the complex, we have synthesized a ligand, $\mathbf{H L}^{\mathbf{1}}=2$ methoxy-6-((2-(2-hydroxyethylamino)ethylimino)methyl) phenol, which is structurally similar to HL. The only difference being the presence of bromine atom in $\mathbf{H L}^{\mathbf{1}}$. Using this ligand, we eventually got success in synthesizing a complex, $(\mu$ $\mathbf{O})_{2}\left[\mathbf{V}(\mathbf{O})\left(\mathbf{L}^{\mathbf{1}}\right)\right]_{2}$, structurally similar to the reported complex $(\boldsymbol{\mu}-$ $\mathbf{O})_{2}[\mathbf{V}(\mathbf{O})(\mathbf{L})]_{2}$. The complex $(\boldsymbol{\mu}-\mathbf{O})_{2}\left[\mathbf{V}(\mathbf{O})\left(\mathbf{L}^{\mathbf{1}}\right)\right]_{2}$ has been prepared in an identical procedure (Scheme 2$)$ to that of $(\boldsymbol{\mu}-\mathbf{O})_{2}[\mathbf{V}(\mathbf{O})(\mathbf{L})]_{2}$. It is also a $\mu_{2}$-oxo bridged dimer similar to our investigated complex. Unlike $(\boldsymbol{\mu}-\mathbf{O})_{2}[\mathbf{V}(\mathbf{O})(\mathbf{L})]_{2}$, which crystallizes in triclinic space group $P \overline{1},(\boldsymbol{\mu}-\mathbf{O})_{2}\left[\mathbf{V}(\mathbf{O})\left(\mathbf{L}^{\mathbf{1}}\right)\right]_{2}$ crystallizes in orthorhombic space group Pbca. Perspective view of $(\boldsymbol{\mu}-\mathbf{O})_{2}\left[\mathbf{V}(\mathbf{O})\left(\mathbf{L}^{\mathbf{1}}\right)\right]_{2}$ with relative atom numbering scheme is shown in Fig. 2, while crystallographic data, selected bond lengths and bond angle values are given in Tables S2-S4 of ESI, $\dagger$ respectively. There are several other examples ${ }^{42}$ of similar vanadium systems where the other substituents in the benzene ring of the ligand consequently lead to the same $\mu_{2}$-oxo bridged dinuclear complexes described here. Referring to these facts, it can be concluded that variation of substituents on the ligand has practically minimal or no effect in the final structure of vanadium complexes. Table 1 shows few examples of similar vanadium complexes having different substituents in the benzene ring of similar type of ligands.

\subsection{Theoretical studies}

The theoretical study is dedicated to analyze the energy responsible to the extensive hydrogen bonding in the complex. Moreover, the co-existence of two different conformations (pendant arms in Fig. 3) in the solid state structure has also been investigated, which provokes the formation of either intraor inter-molecular hydrogen bonds, as further described below.

Emphasis has been put on the analysis of the two different conformation adopted by the $-\mathrm{CH}_{2}-\mathrm{CH}_{2}-\mathrm{OH}$ pendant arm in the complex. As shown in Fig. 3, two different conformers coexist in the same crystal structure. In one case, the hydroxyl groups point to the oxygen atoms of the $\mathrm{VO}_{2}{ }^{+}$cation, forming intra-molecular hydrogen bonds. In the other case, the hydroxyl groups are not establishing intra-molecular hydrogen bonds (small arrows in Fig. 3, right). The conformer with intra-

Table 2 Comparison of intra-molecular $\mathrm{O}-\mathrm{H} \cdots \mathrm{O}$ hydrogen bond distance of the investigated complex with structurally similar reported complexes

\begin{tabular}{llll}
\hline Complexes & $\begin{array}{l}\text { CCDC numbers/ } \\
\text { codes }\end{array}$ & $\begin{array}{l}\mathrm{O}-\mathrm{H}^{\cdots} \mathrm{O} \\
\text { distances (in } \AA)\end{array}$ & References \\
\hline$(\mu-\mathbf{O})_{2}\left[\mathbf{V}(\mathbf{O})\left(\mathbf{L}^{2}\right)\right]_{2}$ & KACRUB03 & $1.967(2)$ & $42 a$ \\
$(\mu-\mathbf{O})_{2}\left[\mathbf{V}(\mathbf{O})\left(\mathbf{L}^{2}\right)\right]_{2}$ & KACRUB04 & $1.84(4)$ & $15 a$ \\
$(\mu-\mathbf{O})_{2}\left[\mathbf{V}(\mathbf{O})\left(\mathbf{L}^{5}\right)\right]_{2}$ & ROHTEP & $1.949(1)$ & $42 c$ \\
$(\mu-\mathbf{O})_{2}\left[\mathbf{V}(\mathbf{O})\left(\mathbf{L}^{6}\right)\right]_{2}$ & TECQEZ & $1.94(7)$ & $42 d$ \\
$(\mu-\mathbf{O})_{2}[\mathbf{V}(\mathbf{O})(\mathbf{L})]_{2}$ & 1879621 & 1.92 & This work
\end{tabular}
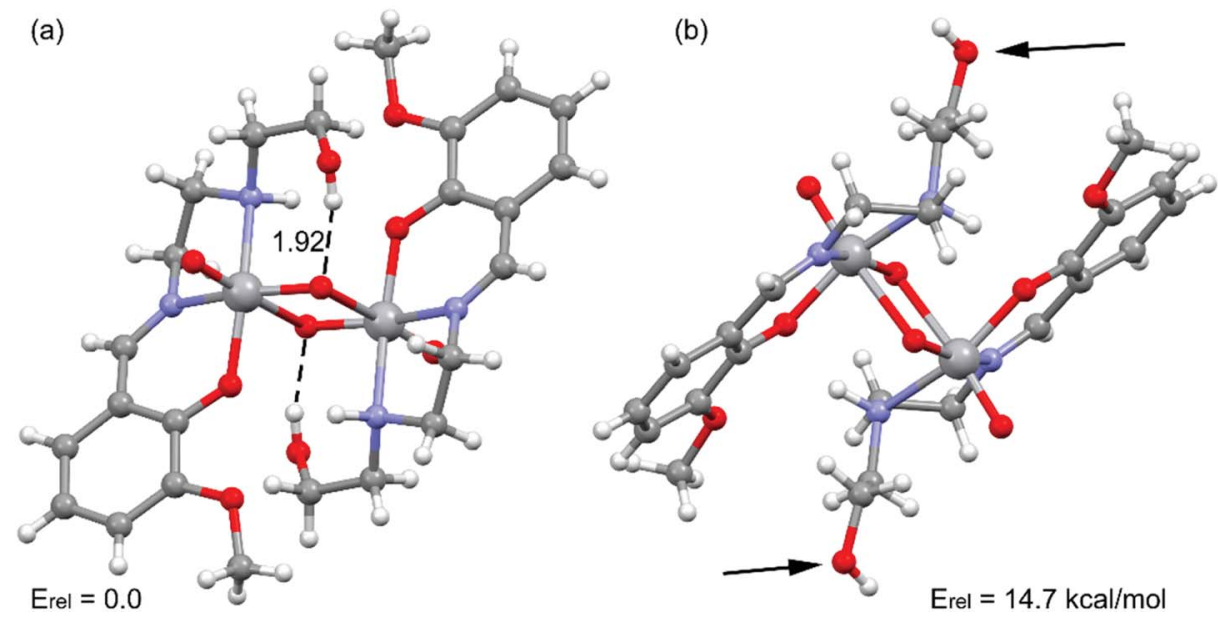

Fig. 3 Partial view of the solid state structure of the complex. Distance in $\AA$. The relative energy of both conformations is also indicated. 


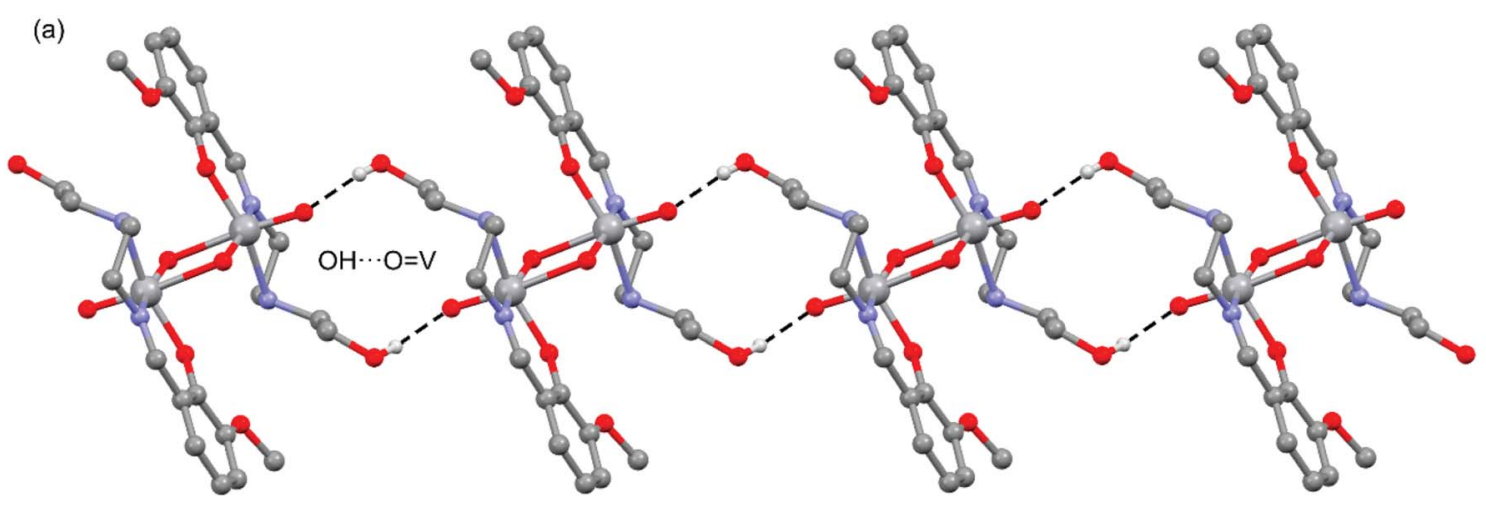

(b)

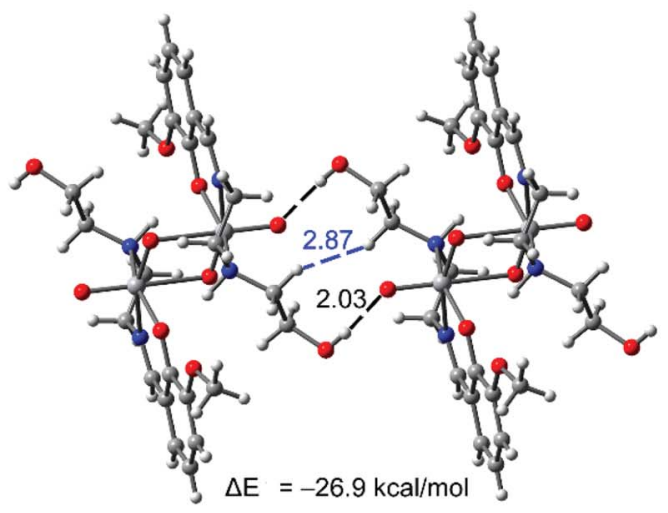

X-ray

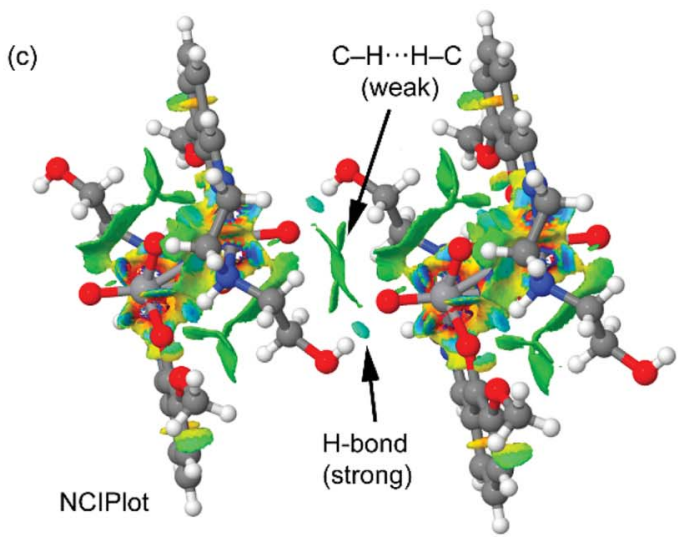

Fig. 4 (a) 1D supramolecular chain observed in the solid state structure of the complex. Non-polar hydrogen atoms have been omitted for clarity. (b) Dimer retrieved from the crystal structure of the complex. Distances in $\AA$. (c) $\mathrm{NCl}$ surface of the hydrogen bonded dimer of the complex. The gradient cut-off is $s=0.35 \mathrm{au}$, and the color scale is $-0.04<\rho<0.04$ au.

molecular hydrogen bonds is $14.7 \mathrm{kcal} \mathrm{mol}^{-1}$ more stable than the other, suggesting that each hydrogen bond stabilizes the conformation in approximately $7.35 \mathrm{kcal} \mathrm{mol}^{-1}$. The intramolecular $\mathrm{O}-\mathrm{H} \cdots \mathrm{O}$ distance has been found to be $1.92 \AA$. This is similar to the intra-molecular $\mathrm{O}-\mathrm{H} \cdots \mathrm{O}$ distances found in structurally similar vanadium(v) complexes (Table 2). ${ }^{15 a, 42 a, c, \boldsymbol{d}}$ The existence of the other conformer is due to its crucial participation in the formation of a supramolecular 1D chain in the solid state governed by inter-molecular instead of intramolecular $\mathrm{O}-\mathrm{H} \cdots \mathrm{O}$ hydrogen bonds as shown in Fig. 4a. The interaction energy of one dimer extracted from the $1 \mathrm{D}$ chain is large and negative $\left(\Delta E=-26.9 \mathrm{kcal} \mathrm{mol}^{-1}\right.$, Fig. 4b), which clearly explains why this conformation $\left(14.7 \mathrm{kcal} \mathrm{mol}^{-1}\right.$ less favorable) is also present in the solid state. The NCI plot (Fig. 4c) shows the existence of small blue isosurfaces characterizing the hydrogen bonding interactions as strong forces, in agreement with the large binding energy. Moreover, it also reveals the existence of weak van der Waals interactions $(\mathrm{CH} \cdots \mathrm{HC})$ between the hydrogen atoms of the ethylene groups (blue dashed line in Fig. 4b) that also contribute to the stabilization of the supramolecular assembly.

\subsection{Spectral and magnetic study}

Strong and sharp band at $1634 \mathrm{~cm}^{-1}$ due to azomethine $(\mathrm{C}=\mathrm{N})$ group has been routinely noticed in the IR spectrum of the
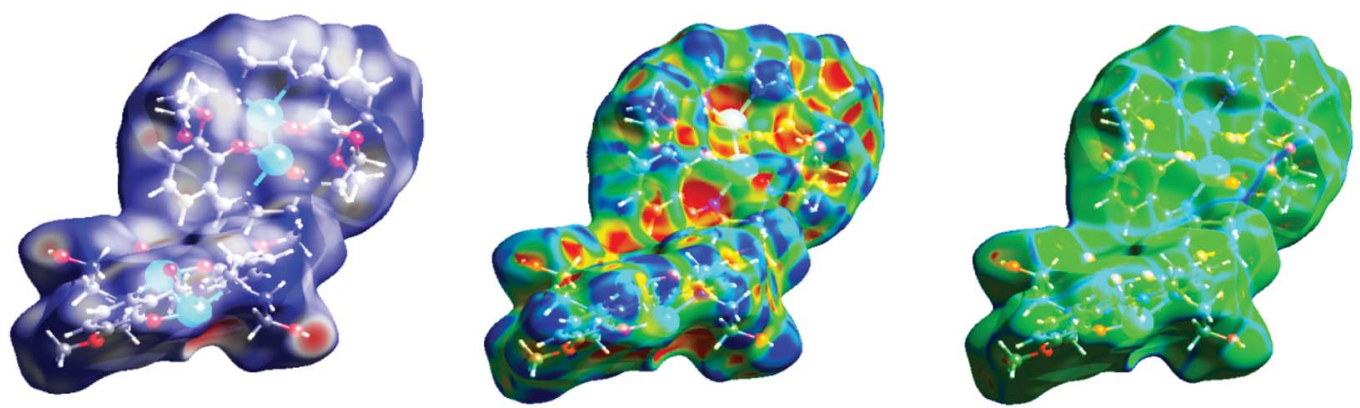

Fig. 5 Hirshfeld surfaces mapped with $d_{\text {norm }}$ (left), shape index (middle) and curvedness (right) of the complex. 
(a)

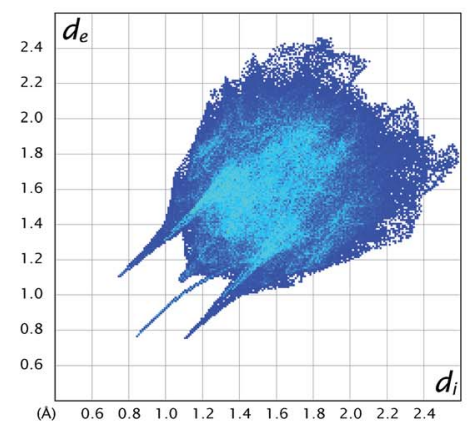

(b)

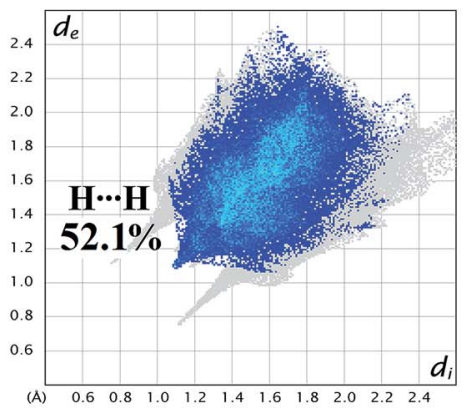

(c)

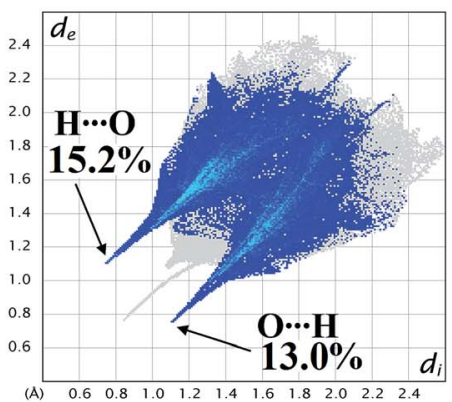

(d)

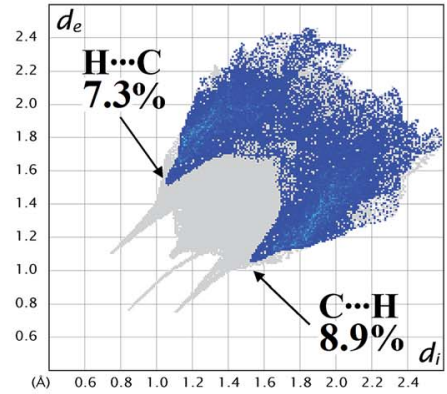

(e)

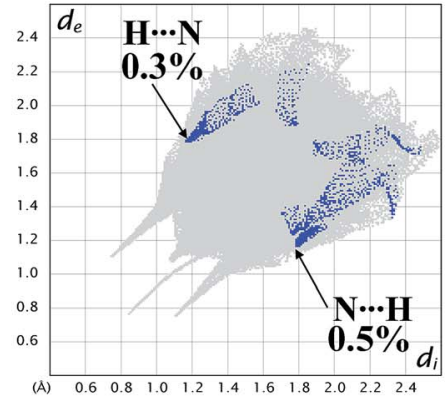

Fig. 6 2D fingerprint plot of the complex showing (a) total surface area; proportions of (b) $\mathrm{H} \cdots \mathrm{H} ;$ (c) $\mathrm{O} \cdots \mathrm{H} / \mathrm{H} \cdots \mathrm{O} ;(\mathrm{d}) \mathrm{C} \cdots \mathrm{H} / \mathrm{H} \cdots \mathrm{C} ;$ (e) $\mathrm{N} \cdots \mathrm{H} / \mathrm{H} \cdots \mathrm{N}$ interactions.

complex..$^{43}$ Existence of strong bands around $934 \mathrm{~cm}^{-1}$ and $825 \mathrm{~cm}^{-1}$ may be assigned to asymmetric and symmetric $\tilde{v}_{(\mathrm{O}=\mathrm{V}=\mathrm{O})}$ vibrations of $c i s-\mathrm{VO}_{2}$ groups. ${ }^{44}$ Sharp band at $3148 \mathrm{~cm}^{-1}$ may be assigned to $\tilde{v}_{(\mathrm{N}-\mathrm{H})}$ stretching vibration ${ }^{45}$ whereas a broad band at $3393 \mathrm{~cm}^{-1}$ indicates the presence of hydrogen bonded alcoholic group in the crystal structure of the complex. ${ }^{46}$ IR spectrum of the complex is shown in Fig. S1, ESI. $\dagger$ Electronic spectrum (Fig. S2, $\mathrm{ESI} \dagger$ ) of the complex in $\mathrm{CH}_{3} \mathrm{CN}$ displays an absorption band at $388 \mathrm{~nm}$, which is indicative of the ligand-to-metal charge transfer
(LMCT) transition originating from the $\mathrm{p}_{\pi}$ orbital on the phenolate oxygen to the empty d orbitals of vanadium(v). ${ }^{47}$

Magnetic susceptibility measurement shows that the complex is diamagnetic, which is quite obvious for any vana$\operatorname{dium}(\mathrm{v})$ complex with no unpaired electrons. ${ }^{48}$

\subsection{Hirshfeld surface analysis}

Hirshfeld surfaces and 2D fingerprint plots of the complex are shown in Fig. 5 and 6 respectively, where inter-molecular

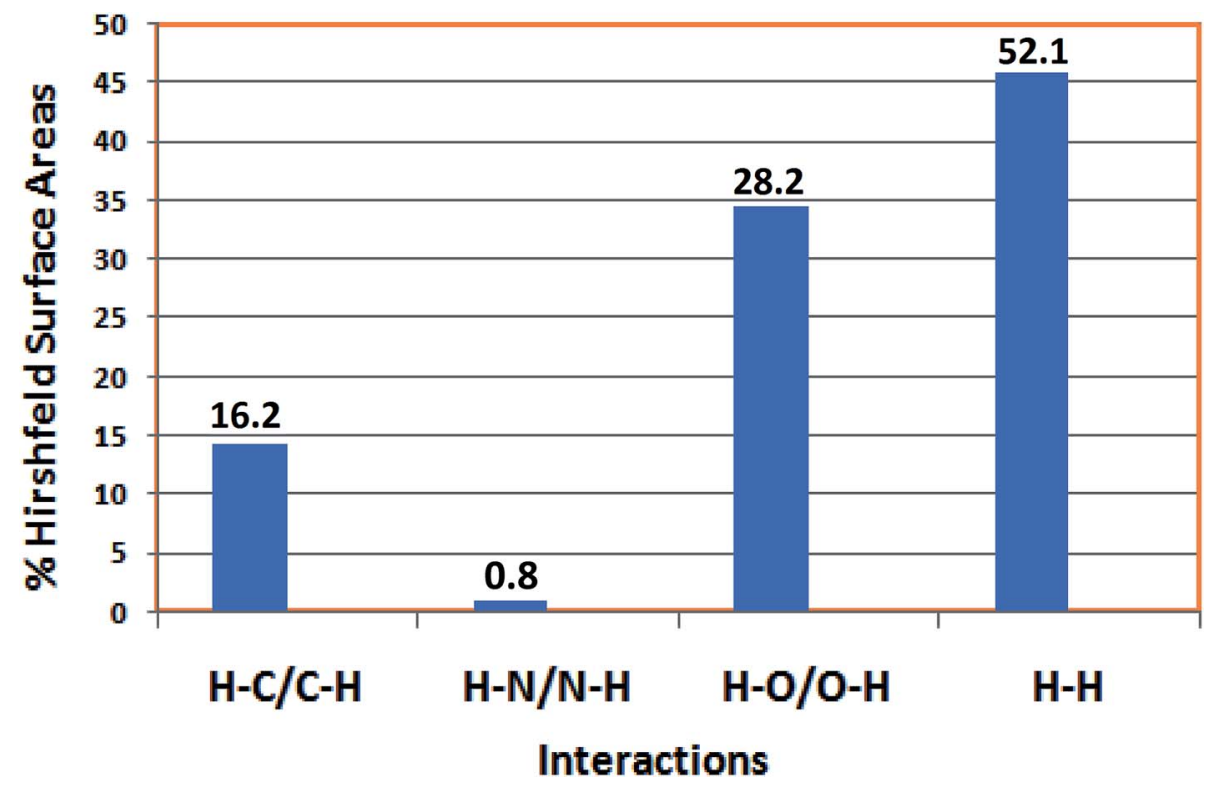

Fig. 7 Relative proportions of interactions in the total Hirshfeld surface area of the complex, represented in a bar diagram. 
interactions appear as discrete spikes. The surfaces are shown as transparent to allow visualization of the molecule, in a similar orientation for all structures, around which they were calculated.

The fingerprint plots are also analyzed to illustrate particular atoms pair close contacts. This decomposition of fingerprint plots enables separation of contributions from different interaction types, which overlap in the full fingerprint. 2D fingerprint plot of the complex shows proportions of $\mathrm{O} \cdots \mathrm{H} / \mathrm{H} \cdots \mathrm{O}$ and $\mathrm{C} \cdots \mathrm{H} / \mathrm{H} \cdots \mathrm{C}$ interactions comprise $28.2 \%$ and $16.2 \%$ of total surface of the complex. The $\mathrm{N} \cdots \mathrm{H} / \mathrm{H} \cdots \mathrm{N}$ interaction is found to be very low i.e. $0.8 \%$. The $\mathrm{H} \cdots \mathrm{H}$ interaction constitutes significant amount of interaction, i.e. $52.1 \%$ of the total Hirshfeld surface (Fig. 7).

The lower spike $\left(d_{\mathrm{i}}=1.12, d_{\mathrm{e}}=0.76 \AA\right)$ of Fig. $6 \mathrm{c}$ indicates $\mathrm{O} \cdots \mathrm{H}$ interaction and the upper spike $\left(d_{\mathrm{i}}=0.76, d_{\mathrm{e}}=1.12 \AA\right)$ indicates $\mathrm{H} \cdots \mathrm{O}$ interaction. Similarly $\mathrm{C} \cdots \mathrm{H}$ interaction is also represented by lower spike $\left(d_{\mathrm{i}}=1.56, d_{\mathrm{e}}=1.06 \AA\right)$ and $\mathrm{H} \cdots \mathrm{C}$ interaction is represented by upper spike $\left(d_{\mathrm{i}}=1.06, d_{\mathrm{e}}=1.56 \AA\right)$ (Fig. 6d).

\section{Conclusion}

A new dinuclear vanadium(v) Schiff base complex, ( $\mu$ $\mathbf{O})_{2}[\mathbf{V}(\mathbf{O})(\mathbf{L})]_{2}$, has been synthesized and structurally characterized. The complex crystallizes in triclinic space group $P \overline{1}$. It consists of two independent dinuclear subunits. Hydrogen bonding interactions in two subunits are different. DFT calculations have been used to estimate the energy associated to the hydrogen bonding interactions present in the complex. NCI plot index computational tool further assists relevant theoretical findings. The competition between inter- and intra-molecular $\mathrm{OH} \cdots \mathrm{O}_{2} \mathrm{~V}^{+}$hydrogen bonds and their influence in the solid state architecture of this complex has been studied accordingly.

\section{Conflicts of interest}

There are no conflicts of interest to declare.

\section{Acknowledgements}

S. T. thanks the DST, India, for awarding a Junior Research Fellowship (IF160359). A. Frontera and A. Franconetti gratefully acknowledge the financial support of this work by the MINECO/ AEI of Spain (project CTQ2017-85821-R, FEDER funds). In addition, AF thanks the MINECO/AEI from Spain for a "Juan de la Cierva" contract. They thank the CTI (UIB) for free allocation of computer time. M. G. B. D. thanks the University of Reading and the EPSRC (U. K.) for funds for the diffractometer.

\section{Notes and references}

1 (a) G. Licini, V. Conte, A. Coletti, M. Mba and C. Zonta, Coord. Chem. Rev., 2011, 255, 2345-2357; (b) Y. Zhang and R. H. Holm, Inorg. Chem., 1990, 29, 911-917; (c) P. Adão, J. C. Pessoa, R. T. Henriques, M. L. Kuznetsov, F. Avecilla, M. R. Maurya, U. Kumar and I. Correia, Inorg. Chem., 2009,
48, 3542-3561; (d) S. K. Hanson, R. T. Baker, J. C. Gordon, B. L. Scott, A. D. Sutton and D. L. Thorn, J. Am. Chem. Soc., 2009, 131, 428-429; (e) G. Santoni, G. Licini and D. Rehder, Chem.-Eur. J., 2003, 9, 4700-4708.

2 (a) P. Knopp, K. Wieghardt, B. Nuber, J. Weiss and W. S. Sheldrick, Inorg. Chem., 1990, 29, 363-371; (b) J. J. H. Edema, W. Stauthamer, E. V. Bolhuis, S. Gambarotta, W. J. J. Smeets and A. L. Spek, Inorg. Chem., 1990, 29, 1302-1306; (c) G. S. Fink, L. G. Cuervo, B. Therrien, H. S. Evans and G. B. Shul'pin, Inorg. Chim. Acta, 2004, 357, 475-484; (d) K. Jonas, B. Gabor, R. Mynott, K. Angermund, O. Heinemann and C. Kriiger, Angew. Chem., Int. Ed. Engl., 1997, 36, 1712-1714; (e) S. L. Castro, W. E. Streib, J.-S. Sun and G. Christou, Inorg. Chem., 1996, 35, 4462-4468; (f) H. Zhu, Q. Liu, Y. Deng, T. Wen, C. Chen and D. Wu, Inorg. Chim. Acta, 1999, 286, 7-13; (g) X.-M. Zhang, M.-L. Tong, H. K. Lee and X.-M. Chen, J. Solid State Chem., 2001, 160, 118-122; (h) A. Z. E. Sonbati, A. A. M. Belal, M. A. Diab and M. Z. Balboula, Spectrochim. Acta, Part A, 2011, 78, 1119-1125.

3 (a) L. M. Mokry and C. J. Carrano, Inorg. Chem., 1993, 32, 6119-6121; (b) S.-S. Qian, Z.-L. You, Y.-N. Li, X. Hu, M. Zhang and H.-L. Zhu, J. Coord. Chem., 2013, 66, 13111319.

4 (a) A. Escande, L. Guénée, K.-L. Buchwalder and C. Piguet, Inorg. Chem., 2009, 48, 1132-1147; (b) L. Saghatforoush, Main Group Chem., 2015, 14, 115-125; (c) M. Chen, M. Hu, H. Zhao, J.-Y. Tian and C.-S. Liu, Z. Anorg. Allg. Chem., 2016, 642, 778-784; (d) G. Mahmoudi, A. A. Khandar, J. K. Zaręba, M. J. Białek, M. S. Gargari, M. Abedi, G. Barandika, D. V. Derveer, J. Mague and A. Masoumi, Inorg. Chim. Acta, 2015, 429, 1-14; (e) A. K. Cheetham, G. Kieslich and H. H.-M. Yeung, Acc. Chem. Res., 2018, 51, 659-667; $(f)$ M. Chen, Z.-W. Wang, H. Zhao and C.-S. Liu, Inorg. Chem. Commun., 2014, 45, 84-88; (g) D. P. Malenov, G. V. Janjić, V. B. Medaković, M. B. Hall and S. D. Zaric, Coord. Chem. Rev., 2017, 345, 318-341.

5 (a) E. R. Johnson, S. Keinan, P. M. Sánchez, J. C. García, A. J. Cohen and W. Yang, J. Am. Chem. Soc., 2010, 132, 6498-6506; (b) S. Fang, S. Y.-L. Leung, Y. Li and V. W.-W. Yam, Chem.-Eur. J., 2018, 24, 15596-15602; (c) Z. P. Shields, J. S. Murray and P. Politzer, Int. J. Quantum Chem., 2010, 110, 2823-2832.

6 (a) C. Schmuck and W. Wienand, Angew. Chem., Int. Ed., 2001, 40, 4363-4369; (b) H. Guo and M. Karplus, J. Phys. Chem., 1994, 98, 7104-7105; (c) L.-S. Teo, C.-Y. Chen and J.-F. Kuo, Macromolecules, 1997, 30, 1793-1799.

7 (a) L. J. Barbour, G. W. Orr and J. L. Atwood, Nature, 1998, 393, 671-673; (b) H. W. Roesky and M. Andruh, Coord. Chem. Rev., 2003, 236, 91-119; (c) F. Wang, M. A. J. Gillissen, P. J. M. Stals, A. R. A. Palmans and E. W. Meijer, Chem.-Eur. J., 2012, 18, 11761-11770.

8 (a) A. Bouchet, J. Klyne, S.-I. Ishiuchi, O. Dopfer, M. Fujii and A. Zehnacker, Phys. Chem. Chem. Phys., 2018, 20, 1243012443; (b) L. Pauling, R. B. Corey and H. R. Branson, Proc. Natl. Acad. Sci. U. S. A., 1951, 37, 205-211; (c) C. M. Dobson, Nature, 2003, 426, 884-890. 
9 F. D. Rochon, M. Andruh and R. Melanson, Can. J. Chem., 1998, 76, 1564-1570.

10 R. R. Fenton, L. F. Lindoy, R. C. Luckay, F. R. Turville and G. Wei, Aust. J. Chem., 2002, 54, 59-62.

11 (a) M. Vicente, R. Bastida, C. Lodeiro, A. Macías, A. J. Parola, L. Valencia and S. E. Spey, Inorg. Chem., 2003, 42, 6768-6779; (b) M. Woods, D. E. Woessner, P. Zhao, A. Pasha, M.-Y. Yang, C.-H. Huang, O. Vasalitiy, J. R. Morrow and A. D. Sherry, J. Am. Chem. Soc., 2006, 128, 10155-10162; (c) T. Mani, A. C. L. Opina, P. Zhao, O. M. Evbuomwan, N. Milburn, G. Tircso, C. Kumas and A. D. Sherry, J. Biol. Inorg Chem., 2014, 19, 161-171; (d) C. Stockheim, L. Hater, T. Weyhermiiller, K. Wieghardt and B. Nuber, J. Chem. Soc., Dalton Trans., 1996, 4409-4416; (e) K. S. Min and M. P. Suh, Eur. J. Inorg. Chem., 2001, 449-455.

12 H. Aneetha, Y.-H. Lai, S.-C. Lin, K. Panneerselvam, T.-H. Lu and C.-S. Chung, J. Chem. Soc., Dalton Trans., 1999, 28852892.

13 M. K. C. T. Nagata, P. S. Brauchle, S. Wang, S. K. Briggs, Y. S. Hong, D. W. Laorenza, A. G. Lee and T. D. Westmoreland, Polyhedron, 2016, 114, 299-305.

14 (a) K. Chattopadhyay, G. A. Craig, A. Kundu, V. Bertolasi, M. Murrie and D. Ray, Inorg. Chem., 2016, 55, 1078310792; (b) W. J. Lian, X.-T. Wang, C.-Z. Xie, H. Tian, X.-Q. Song, H.-T. Pan, X. Qiao and J.-Y. Xu, Dalton Trans., 2016, 45, 9073-9087.

15 (a) X. Li, M. S. Lah and V. L. Pecoraro, Inorg. Chem., 1988, 27, 4657-4664; (b) C. R. Cornman, G. J. Colpas, J. D. Hoeschele, J. Kampf and V. L. Pecoraro, J. Am. Chem. Soc., 1992, 114, 9925-9933; (c) S.-Y. Liu and Y.-P. Ma, Synth. React. Inorg., Met.-Org., Nano-Met. Chem., 2012, 42, 603-607; (d) K.-H. Yang, Transition Met. Chem., 2014, 39, 469-475.

16 D. Sanna, J. Palomba, G. Lubinu, P. Buglyó, S. Nagy, F. Perdih and E. Garribba, J. Med. Chem., 2019, 62, 654-664. 17 (a) D. C. Crans, J. T. Koehn, S. M. Petry, C. M. Glover, A. Wijetunga, R. Kaur, A. Levina and P. A. Lay, Dalton Trans., 2019, 48, 6383-6395; (b) Z. Kazemi, H. A. Rudbari, V. Mirkhani, M. Sahihi, M. Moghadam, S. Tangestaninejad, I. Mohammadpoor-Baltork, A. A. Kajani and G. Azimi, Eur. J. Med. Chem., 2017, 135, 230-240.

18 O. A. Chavesa, M. C. C. de Oliveira, C. M. C. de Salles, F. M. Martins, B. A. Iglesiase and D. F. Back, J. Inorg. Biochem., 2019, 200, 110800.

19 L.-Y. He, X.-Y. Qiu, J.-Y. Cheng, S.-J. Liu and S.-M. Wu, Polyhedron, 2018, 156, 105-110.

20 D. Dragancea, N. Talmaci, S. Shova, G. Novitchi, D. Darvasiová, P. Rapta, M. Breza, M. Galanski, J. Kož̌šěk, N. M. R. Martins, L. M. D. R. S. Martins, A. J. L. Pombeiro and V. B. Arion, Inorg. Chem., 2016, 55, 9187-9203.

21 P. Adak, B. Ghosh, B. Pakhira, R. Sekiya, R. Kuroda and S. K. Chattopadhyay, Polyhedron, 2017, 127, 135-143.

22 (a) G. M. Sheldrick, Acta Crystallogr., Sect. A: Found. Crystallogr., 2008, 64, 112-122; (b) G. M. Sheldrick, Acta Crystallogr., Sect. C: Struct. Chem., 2015, 71, 3-8.

23 A. L. Spek, Acta Crystallogr., Sect. D: Biol. Crystallogr., 2009, 65, 148-155.
24 J. L. Farrugia, J. Appl. Crystallogr., 2012, 45, 849-854.

25 M. N. Burnett and C. K. Johnson, ORTEP-3: Oak Ridge Thermal Ellipsoid Plot Program for Crystal Structure Illustrations, Report ORNL-6895, Oak Ridge National Laboratory, Oak Ridge, TN, USA, 1996.

26 C. F. Macrae, I. J. Bruno, J. A. Chisholm, P. R. Edgington, P. McCabe, E. Pidcock, L. R. Monge, R. Taylor, J. V. D. Streek and P. A. Wood, J. Appl. Crystallogr., 2008, 41, 466-470.

27 M. J. Frisch, G. W. Trucks, H. B. Schlegel, G. E. Scuseria, M. A. Robb, J. R. Cheeseman, G. Scalmani, V. Barone, B. Mennucci, G. A. Petersson, H. Nakatsuji, M. Caricato, X. Li, H. P. Hratchian, A. F. Izmaylov, J. Bloino, G. Zheng, J. L. Sonnenberg, M. Hada, M. Ehara, K. Toyota, R. Fukuda, J. Hasegawa, M. Ishida, T. Nakajima, Y. Honda, O. Kitao, H. Nakai, T. Vreven, J. A. Montgomery Jr, J. E. Peralta, F. Ogliaro, M. Bearpark, J. J. Heyd, E. Brothers, K. N. Kudin, V. N. Staroverov, R. Kobayashi, J. Normand, K. Raghavachari, A. Rendell, J. C. Burant, S. S. Iyengar, J. Tomasi, M. Cossi, N. Rega, J. M. Millam, M. Klene, J. E. Knox, J. B. Cross, V. Bakken, C. Adamo, J. Jaramillo, R. Gomperts, R. E. Stratmann, O. Yazyev, A. J. Austin, R. Cammi, C. Pomelli, J. W. Ochterski, R. L. Martin, K. Morokuma, V. G. Zakrzewski, G. A. Voth, P. Salvador, J. J. Dannenberg, S. Dapprich, A. D. Daniels, Ö. Farkas, J. B. Foresman, J. V. Ortiz, J. Cioslowski and D. J. Fox, Gaussian 09, Gaussian, Inc., Wallingford CT, 2009. 28 (a) S. Ghosh, S. Biswas, A. Bauzá, M. Barceló-Oliver, A. Frontera and A. Ghosh, Inorg. Chem., 2013, 52, 75087523; (b) J. Adhikary, P. Chakraborty, S. Das, T. Chattopadhyay, A. Bauzá, S. K. Chattopadhyay, B. Ghosh, F. A. Mautner, A. Frontera and D. Das, Inorg. Chem., 2013, 52, 13442-13452; (c) M. S. Gargari, V. Stilinović, A. Bauzá, A. Frontera, P. McArdle, D. Van Derveer, S. W. Ng and G. Mahmoudi, Chem.-Eur. J., 2015, 21, 17951-17958; (d) M. Mirzaei, H. Eshtiagh-Hosseini, Z. Bolouri, Z. Rahmati, A. Esmaeilzadeh, A. Hassanpoor, A. Bauzá, P. Ballester, M. Barceló-Oliver, J. T. Mague, B. Notash and A. Frontera, Cryst. Growth Des., 2015, 15, 1351-1361.

29 S. F. Boys and F. Bernardi, Mol. Phys., 1970, 19, 553-566.

30 J. C. García, E. R. Johnson, S. Keinan, R. Chaudret, J.-P. Piquemal, D. N. Beratan and W. Yang, J. Chem. Theory Comput., 2011, 7, 625-632.

31 (a) M. A. Spackman and D. Jayatilaka, CrystEngComm, 2009, 11, 19-32; (b) F. L. Hirshfeld, Theor. Chim. Acta, 1977, 44, 129-138; (c) H. F. Clausen, M. S. Chevallier, M. A. Spackman and B. B. Iversen, New J. Chem., 2010, 34, 193-199.

32 (a) A. L. Rohl, M. Moret, W. Kaminsky, K. Claborn, J. J. McKinnon and B. Kahr, Cryst. Growth Des., 2008, 8, 4517-4525; (b) A. Parkin, G. Barr, W. Dong, C. J. Gilmore, D. Jayatilaka, J. J. McKinnon, M. A. Spackman and C. C. Wilson, CrystEngComm, 2007, 9, 648-652.

33 S. K. Wolff, D. J. Grimwood, J. J. McKinnon, D. Jayatilaka and M. A. Spackman, Crystal Explorer 2.0, University of Western 
Australia, Perth, Australia, 2007, http:// hirshfeldsurfacenet.blogspot.com.

34 J. J. McKinnon, M. A. Spackman and A. S. Mitchell, Acta Crystallogr., Sect. B: Struct. Sci., 2004, 60, 627.

35 S. Ghosh, N. Hari, D. Pinkowicz, M. Fitta and S. Mohanta, New J. Chem., 2018, 42, 15917-15929.

36 (a) A. Sarkar and S. Pal, Polyhedron, 2007, 26, 1205-1210; (b) S. Pal and S. Pal, J. Chem. Crystallogr., 2000, 30, 329-333.

37 G. J. Colpas, B. J. Hamstra, J. W. Kampf and V. L. Pecoraro, Inorg. Chem., 1994, 33, 4669-4675.

38 S. Rayati, N. Sadeghzadeh and H. R. Khavasi, Inorg. Chem. Commun., 2007, 10, 1545-1548.

39 C. J. Carrano, C. M. Nunn, R. Quan, J. A. Bonadies and V. L. Pecoraro, Inorg. Chem., 1990, 29, 944-951.

40 (a) D. Cremer and J. A. Pople, J. Am. Chem. Soc., 1975, 97, 1354-1358; (b) D. Cremer, Acta Crystallogr., 1984, B40, 498500.

41 A. D. French, Advances in Carbohydrate Chemistry and Biochemistry, Academic Press, Science, 2012, vol. 67, p. 24.

42 (a) M.-J. Xie, Y.-F. Niu, X.-D. Yang, W.-P. Liu, L. Li, L.-H. Gao, S.-P. Yan and Z.-H. Meng, Eur. J. Med. Chem., 2010, 45, 60776084; (b) Z.-L. You, D.-H. Shi, J.-C. Zhang, Y.-P. Maa, C. Wang and K. Li, Inorg. Chim. Acta, 2012, 384, 54-61; (c) K.-H. Yang, Transition Met. Chem., 2014, 39, 469-475; (d) S.-Y. Liu and Y.-P. Ma, Synth. React. Inorg., Met.-Org., Nano-Met. Chem., 2012, 42, 603-607; (e) F. Xu, L.-W. Xue and C.-X. Zhang, Synth. React. Inorg., Met.-Org., Nano-Met. Chem., 2015, 45, 1678-1682; (f) M. Ghorbani, A. D. Khalaji, N. Feizi, A. Akbari, V. Eigner and M. Dusek, J. Mol. Struct., 2017, 1130, 442-446.

43 S. Chattopadhyay, M. S. Ray, S. Chaudhuri, G. Mukhopadhyay, G. Bocelli, A. Cantoni and A. Ghosh, Inorg. Chim. Acta, 2006, 359, 1367-1375.

44 Y. Abe, A. Iyoda, K. Seto, A. Moriguchi, T. Tanase and H. Yokoyama, Eur. J. Inorg. Chem., 2008, 2148-2157.

45 (a) L. Sacconi and I. Bertini, J. Am. Chem. Soc., 1966, 88, 5180-5185; (b) N. Raman, Y. P. Raja and A. Kulandaisamy, J. Chem. Sci., 2001, 113, 183-189.

46 G. Cros and J.-P. Laurent, Inorg. Chim. Acta, 1985, 105, 63-67. 47 B. Mondal, T. Ghosh, M. Sutradhar, G. Mukherjee, M. G. B. Drew and T. Ghosh, Polyhedron, 2008, 27, 21932201.

48 A. Niemann, U. Bossek, G. Haselhorst, K. Wieghardt and B. Nuber, Inorg. Chem., 1996, 35, 906-915. 